\title{
An Innovative Program Using Magic to Provide Early Clinical Experiences for Preclinical Medical Students: Goals, Experiences, and Results of the MagicAid Program
}

\author{
Harrison D. Pravder ${ }^{1,2}\left(\right.$ D $\cdot$ David J. Elkin ${ }^{1,2} \cdot$ Stephen G. Post ${ }^{3} \cdot$ Maribeth B. Chitkara $^{4}(\mathbb{C}$
}

Accepted: 19 October 2021 / Published online: 14 January 2022

(c) The Author(s) under exclusive licence to International Association of Medical Science Educators 2021

\begin{abstract}
Objective Effectively training medical students in compassion, communication, and empathy is essential in fostering a holistic approach to patient care. We sought to address this by implementing an early clinical experience service learning program for medical students in the initial years of their medical education.

Methods Medical students at Stony Brook University initiated, designed, and facilitated the volunteer program, which provides students a framework to learn magic therapy and engage with pediatric patients. The program includes an introductory presentation, training course, and organized bedside sessions with patients. To evaluate the program, a sample of participants partook in a focus group, written questionnaire, and/or online survey.

Results From 2015 to 2020, 130 students participated in magic therapy rounds, engaging 1391 patients. Nine themes of student benefit emerged from qualitative analysis, including acquisition of familiarity with the hospital and healthcare team, cultivation of communication skills, contribution to improvement of patient affect, development of empathic qualities and techniques, and improvement in psychological health. Students were very satisfied with their experiences and viewed the activity as helpful for patients, parents, staff, and themselves.

Conclusions The program engaged students in compassionate patient care within a holistic approach to patient care early in training.
\end{abstract}

Keywords Undergraduate medical education · Early clinical experience $\cdot$ Preclinical $\cdot$ Magic $\cdot$ Medical students $\cdot$ Service learning

\section{Introduction}

"Disease" refers to the biological dysfunction of organs and systems that present a puzzle for differential diagnosis [1]. "Illness," however, pertains to the ways in which

Harrison D. Pravder

harrison.pravder@yale.edu

1 Renaissance School of Medicine, Stony Brook University, 100 Nicolls Road, Stony Brook, NY 11794, USA

2 MagicAid, Great Neck, NY 11021, USA

3 Center for Medical Humanities, Department of Family, Population and Preventive Medicine, Compassionate Care and Bioethics, Stony Brook University, HSC, Level 3, Suite 080, Stony Brook, NY 11794, USA

4 Department of Pediatrics, Stony Brook Children's, 101 Nicolls Road, Stony Brook, NY 11794, USA disease is subjectively experienced through social networks, hopes, fears, spirituality, and values - all of which are important to address in the treatment of the "whole patient" [1]. While understanding the illness experience is pivotal to optimal patient treatment, many medical students and professionals become overly detached from their patients' experience [2, 3]. In an effort to avoid overobjectification and over-biologization among medical students, early clinical experiences (ECEs) were developed to elevate student awareness of the patient illness experience and thereby elicit in students the core empathic virtues such as attentive listening, humility, compassion, respect, and similar character strengths. In turn, student rational knowledge and technical skill sets are strengthened. These collectively contribute to the healing and well-being of patients and families.

ECEs are preclerkship programs with direct patient contact that enhance learning [4]. They often take the form of 
clinical placements where students work directly with a clinician; other programs involve clinical skills training, community service experiences, or longitudinal assignments to a single patient or family [5]. They can be daunting experiences for students $[6,7]$ yet help them become familiar with the context of medical care [5], interact more comfortably with ill patients [8, 9], and cultivate self-reflection tools [4].

One field that provides a framework for novel ECE programs is that of medical humanities. Medical humanities is not a new entity; its roots were sewn nearly 100 years ago $[10,11]$. However, its increasing importance to medical education lies in modern medicine's growth of knowledge in congruence with the importance of holistic medicine. Strategies employed through a medical humanities lens include structured practice of narrative writing about the illness experience of the patient and of what the student feels in response to it, reading about illness experiences or carefully observing visual artistic renditions of them, providing small groups for student reflection to bring the human side of their clinical experience into circles of empathic trust and confidential discussion, participating in performance arts allowing for internal expression and practice of interpersonal communication, and empathy training $[10,12]$. Such programs utilize humanity techniques for enhanced student insights into the illness experience from which their empathy can unfold. Humanities in medicine have the potential to help trainees cope with stress, mitigate burnout, maintain empathy, promote well-being, and improve personal qualities [13-16]. Limited descriptions of ECE programs that engage preclinical medical students with patients through similar activities have been described $[17,18]$.

The field under discussion in this work is magic, which falls into the realm of medical humanities as a performance art. Magic aims to foster enjoyment by observation of the impossible through misdirection and "forced" choice, and it requires precise communication of the practitioner to elicit the desired effect. This provides a framework that can be powerfully used in the process of healing and empathy training. And, it has been used as such elsewhere. Both Lam et al. [19] and Bagienski et al. [20] recently reviewed how magic can be used in a wide spectrum of clinical contexts, ranging from physical rehabilitation [21-23] to alleviation of anxiety in the perioperative setting [24]. Further, Dr. Pitt recently explained how magic techniques can be used to improve clinical encounters and communication between pediatricians and child patients [25]. Thus, it has been demonstrated that magic can be powerfully used to improve clinical outcomes and team communication.

With these concepts in mind, we created MagicAid, a voluntary service learning program that facilitates medical student engagement with pediatric patients during the preclinical years through magic performance [26]. Preclinical students interact with hospitalized pediatric patients in the setting of a magic therapy session. The sessions include performance of interactive magic at the bedside and teaching the patient how to present magic themselves. MagicAid allows students to (1) engage in active patient care, (2) serve as primary communicators with patients, and (3) act as the main administrators and evaluators of the program. All is done within a necessarily empathic framework. This paper describes the components, goals, implementation, and outcomes of the program and reports student responses to these experiences.

\section{Materials and Methods}

\section{The MagicAid Program}

In 2014, the MagicAid program was introduced at Renaissance School of Medicine (RSOM) at Stony Brook University in Stony Brook, NY, USA. The medical school is predominantly a 4-year MD-granting institution that employs a $1.5+2.5$ curriculum, consisting of 1.5 years of classroom learning (preclinical) followed by 2.5 years of clinic-based education (clinical). The voluntary service group provides an organized framework for preclinical medical students to gain firsthand pediatric patient exposure early in medical school. Specific goals are noted in Table 1.

Students learn to use magic as a therapeutic intervention to help alleviate pediatric patient stressors associated with hospitalization through "magic therapy" sessions [26]. A magic therapy session involves a trained student magic therapist engaging a patient with magic tricks at the bedside and teaching the patient how to perform magic themselves. Students manage all aspects of the program including recruiting and training volunteers, organizing magic therapy sessions, engaging patients in therapy, and conducting research to assess therapy impacts. Our program receives supplemental financial support from the School of Medicine, Child Life Services, student fundraising efforts, and the MagicAid 501(c)(3) non-profit organization. The program was piloted in academic year (AY) 2015 (August 2015 to May 2016) and established as detailed below in AY 2016 with continuing activity to present.

\section{Student Introduction to the Program}

Medical students are introduced to the program during new student orientation or the first week of classes. During an introductory session, student leaders explain the 


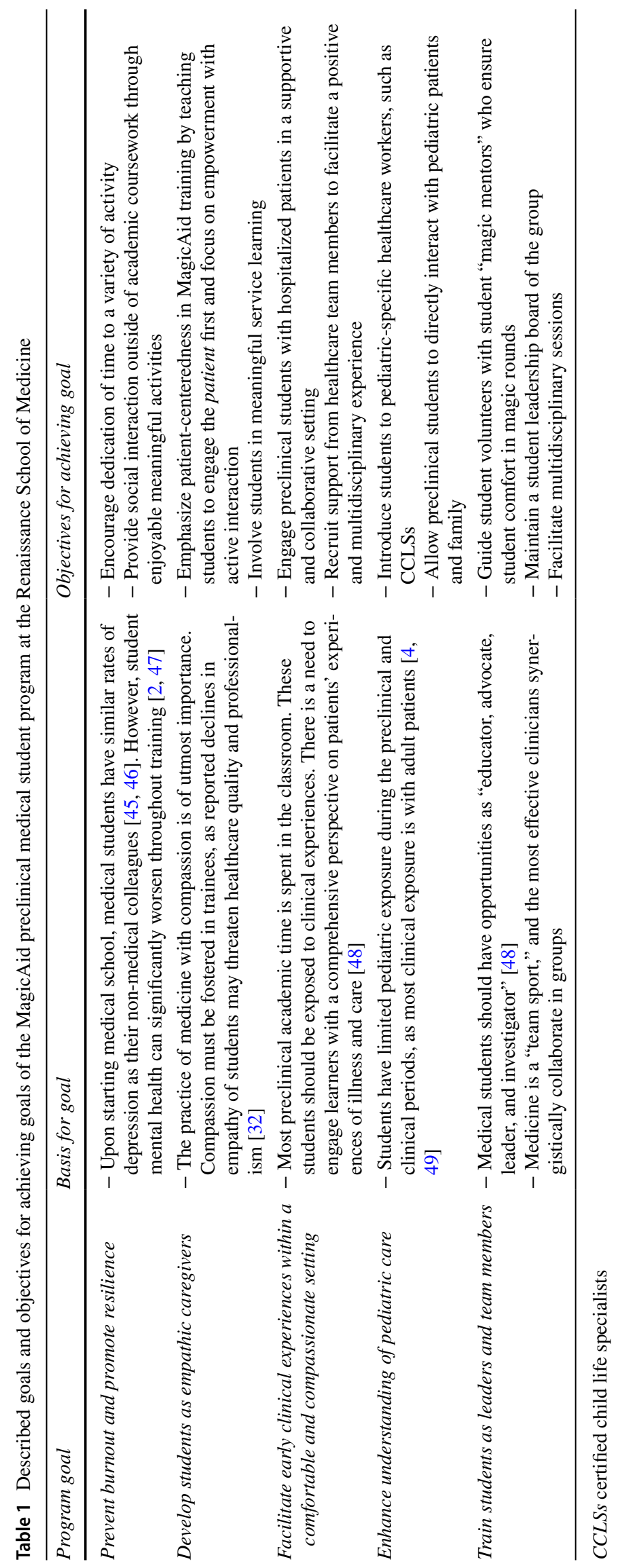


aims and benefits of the experience, ranging from early patient exposure and development of provider identity to team building and personal fulfillment. Previous student experiences within the program are shared, and areas for future growth (i.e., expansion to different clinical settings, research opportunities) are offered. Certified child life specialists (CCLSs), trained professionals who help patients acclimate to the hospital and prepare for interventions through multiple modalities, are invited to attend and share their experiences [27].

\section{Student Engagement in the Program}

In the weeks following the introductory session, training classes are conducted by senior medical students known as "magic mentors"- and thereafter based on demand. There are no prerequisites to attend a training class other than interest in engaging with the program and being a preclinical (year 1 or 2) medical student. During the 1-h training session, students learn to perform five to six basic magic tricks (magic effects). Individual effects are taught to students in a small-group format where they first experience the effect as an audience member, then methods of the effect are divulged, and clinical applications for where the learned techniques may be appropriate to use with patients are described in detail. After the didactic portion of each effect, students practice their newly learned effect on each other. Mentors also teach students how to interact with patients, act professionally in the hospital, and conduct a magic therapy session. By the conclusion of the training session, new therapists receive a complete MagicAid magic therapy set with props. Online video tutorials are also provided for use as refreshers to supplement the in-person sessions.

Upon completion of training, student magic therapists conduct magic rounds on specified hospital units for patients and their families. The rounds are scheduled by student group leaders and CCLS leadership to ensure proper scheduling outside of required academic sessions. Magic round team members include a magic mentor, one to two student therapists, and one CCLS. The CCLS facilitates magic rounds by identifying patients likely to be amenable to magic therapy (based on age, intellectual capacity, diagnosis, etc.). Students present a series of interactive magic tricks, teach the patient to perform one, and leave a prop that allows the patient to master and perform his or her newly learned craft for others. Magic rounds occur up to three times weekly outside of class time and have been conducted in general inpatient pediatric units, pediatric intensive care units, pediatric emergency departments, and outpatient centers. Students are taught proper use of personal protective equipment for use in relevant settings, such as with patients having infectious diseases or on immunocompromised precautions.

\section{Student Reflection on the Program}

Reflection is conducted in formal and informal settings. Structured student-led and organized lunch sessions (with food provided) are hosted during which students discuss methods that they have learned with others, in both communication and technique, and also share their personal experiences. Sessions are designed to encourage team building and promote resilience through community formation and reflective debriefing. These typically occur once per semester and are attended by up to 30 students. Further, informally, students discuss their experiences with each other, magic mentors, and CCLSs during and after magic rounds where timely feedback is provided by magic mentors regarding communication and magic technique. At present, no written feedback or formal assessment is provided to students.

\section{Data Sources and Analysis}

We conducted a mixed-methods study, including a focus group, written reflection questions, and an online survey. The Institutional Review Board at Stony Brook University reviewed and approved this study (ID 1037793, Initial Approval 06/2017). Informed consent was obtained from all student participants.

Preclinical students who were trained and volunteered in the MagicAid program during AY $2017(n=60)$ were invited by email to participate in a 1 -h focus group that was facilitated by a faculty member unknown to study subjects in January 2019. This session included five predetermined open-ended questions (see Supplemental Fig. 1). Participants also completed a written survey with six open-ended questions regarding their MagicAid experiences. The focus group was recorded, and responses were transcribed. Analysis was performed using the general inductive approach to qualitative evaluation for identification of key themes [28]. One investigator (HP) initially read parts of a transcript, developed the initial coding schemata, and identified recurrent themes of program accomplishment. The first investigator then worked with an additional investigator (SP) to determine changes to initially developed codes. Individual comments from the focus group and reflective question transcripts were then analyzed for one or more codes by two authors (HP, SP), which were then grouped into the identified themes.

All students enrolled in our medical school in March 2020 ( $n=539$ ), including those engaged and not engaged in the program, were asked to complete a de-identified survey (Supplemental Fig. 4) using Qualtrics software (Provo, UT, USA). The survey aimed to evaluate program impacts and contained up to 20 questions, including open-ended, yes/ no, and 5-item Likert scale questions. Five questions were 
adapted from a previously developed tool [24]. Eight questions unique to program experience were presented only to volunteers (Table 2).

\section{Results}

\section{MagicAid Program Evaluation}

Of the 539 students who enrolled in our medical school from 2016 to 2019, 209 students completed the MagicAid training curriculum (Table 3; 38.8\% participation rate). Sixty percent of trained students participated in magic rounds on at least one occasion, and $61 \%$ of these students volunteered for more than one session (2-3 rounds: $26 \%, 4-9$ rounds: $18 \%, 10+$ rounds: $17 \%$ ).
From the beginning of AY 2016 to the end of AY 2019, a total of 1391 patients and 122 medical students participated in magic rounds (Table 3 ). Magic round team size averaged two students, and each team saw an average of six patients over a time period of $1 \mathrm{~h}$ and $10 \mathrm{~min}$. Thus, the mean time with each patient was approximately $12 \mathrm{~min}$. A majority of rounds occurred on pediatric inpatient units (58\%), which included general, adolescent, intensive care, and hematology-oncology units. Students also conducted magic rounds in the pediatric emergency department (39\%), outpatient oncologic infusion center $(2 \%)$, and outpatient muscular dystrophy clinic $(2 \%)$.

\section{Focus Group and Reflective Writing}

Seven of 60 eligible students ( $11.7 \%$ participation rate) participated in the focus group and reflective writing exercise,

Table 2 MagicAid participant responses to eight unique questions exploring favorability of involvement in the MagicAid program and the utility of magic therapy

\begin{tabular}{|c|c|}
\hline Survey question & Responses, $N(\%)$ \\
\hline \multicolumn{2}{|l|}{ How satisfied are you with your experiences in MagicAid? } \\
\hline Extremely satisfied & $34(72.34)$ \\
\hline Somewhat satisfied & $10(21.28)$ \\
\hline Neither satisfied nor dissatisfied & $2(4.26)$ \\
\hline Somewhat dissatisfied & $1(2.13)$ \\
\hline Extremely dissatisfied & 0 \\
\hline \multirow{2}{*}{$\begin{array}{l}\text { Did you ever feel that you were a disturbance during a magic therapy } \\
\text { session? }\end{array}$} & Yes: $6(12.5)$ \\
\hline & No: $42(87.5)$ \\
\hline \multirow[t]{2}{*}{ If yes, how so? } & - Disruption of staff workflow $(n=4)$ \\
\hline & - Disruption of patient $(n=1)$ \\
\hline Did you feel welcome in the patient's room during magic rounds? & $\begin{array}{l}\text { Yes: } 47(100) \\
\text { No: } 0(0)\end{array}$ \\
\hline $\begin{array}{l}\text { Did experiences in MagicAid help reduce burnout in the preclinical } \\
\text { years? }\end{array}$ & $\begin{array}{l}\text { Yes: } 28(63.64) \\
\text { No: } 16(36.36)\end{array}$ \\
\hline Did experiences in MagicAid help improve communication skills? & $\begin{array}{l}\text { Yes: } 38(86.36) \\
\text { No: } 6(13.64)\end{array}$ \\
\hline Did you use magic techniques learned in MagicAid with your patients? & $\begin{array}{l}\text { Yes: } 7(24.14) \\
\text { No: } 22(75.86)\end{array}$ \\
\hline If yes, how so? & $\begin{array}{l}\text { - Introductory tool }(n=1) \\
\text { - Changed approach to engaging patient }(n=2) \\
\text { - Used magic with pediatric patients }(n=6) \\
\text { - Used magic with non-pediatric patients }(n=1)\end{array}$ \\
\hline Did experiences in MagicAid help prepare you for clinical rotations? $?^{\mathrm{a}}$ & $\begin{array}{l}\text { Yes: } 15(51.72) \\
\text { No: } 14(48.28)\end{array}$ \\
\hline If yes, how so? & $\begin{array}{l}\text { - Increased comfort while interacting with pediatric patients }(n=2) \text {, } \\
\text { patients (not specifying pediatric) }(n=10) \text {, and patients' families } \\
(n=8) \\
\text { - Increased comfort in approaching patients with terminal illness } \\
(n=1) \text { and initiating a room visit with a child }(n=1) \\
\text { - Increased familiarity with health care team }(n=2) \\
\text { - Helped to see the person behind the patient }(n=1)\end{array}$ \\
\hline $\begin{array}{l}\text { Do you believe that your experiences in MagicAid helped you get accli- } \\
\text { mated to the pediatrics clerkship? }\end{array}$ & $\begin{array}{l}\text { Yes: } 19(65.51) \\
\text { No: } 10(34.48)\end{array}$ \\
\hline
\end{tabular}

${ }^{\mathrm{a}}$ Question only asked of those who had engaged in clinical clerkships 
Table 3 Medical student MagicAid participants at the Renaissance School of Medicine (RSOM), 2015-2020

\begin{tabular}{|c|c|c|c|c|c|c|}
\hline & $\mathrm{EY}^{\mathrm{a}}$ & & & $\mathrm{CY}^{\mathrm{b}}$ & & \\
\hline & Class size & $\begin{array}{l}\text { Trained } \\
\text { students }\end{array}$ & $\begin{array}{l}\text { Rounding } \\
\text { students }\end{array}$ & \# of rounds & Patients seen & Total hours \\
\hline 2015 & 130 & 9 & 8 & 1 & 14 & 2.5 \\
\hline 2016 & 131 & 31 & 20 & 38 & 294 & 53.5 \\
\hline 2017 & 136 & 60 & 34 & 69 & 347 & 75.9 \\
\hline 2018 & 136 & 68 & 36 & 60 & 360 & 73.0 \\
\hline $2019^{c}$ & 136 & 50 & 32 & 68 & 322 & 79.7 \\
\hline $2020^{c}$ & -- & -- & -- & 11 & 54 & 14.4 \\
\hline Total & 669 & 218 & 130 & 247 & 1391 & 299 \\
\hline
\end{tabular}

The bold is present to signify that this row has the total values (all years) whereas all the other cells have singular year data. This row was recommended by peer reviewers

$C Y$ calendar year, $E Y$ entering year

${ }^{a}$ Reflects segregated data based on the EY of students at RSOM. Students joins annually

${ }^{\mathrm{b}}$ Data based on activities during the $\mathrm{CY}$

${ }^{\mathrm{c}}$ As of March 10, 2020, when activities were halted due to the COVID-19 pandemic including four female and three male students. Responses indicated that students enjoyed the program and benefited with the development of communication skills, empathic qualities, leadership techniques, hospital familiarity, and improved psychological health (Table 4). Challenges identified included working with different age groups, mastering the use of magic as a distraction technique during procedures, and learning to adjust performance style in different settings (isolation rooms, emergency department, and inpatient vs outpatient). Students remarked that they were satisfied with the length and availability of magic round sessions such that students could participate in multiple shifts

Table 4 Themes emerging from focus group and written reflections of MagicAid participants $(N=7)$ at the Renaissance School of Medicine and selected representative quotations

\begin{tabular}{lll}
\hline Theme (the student...) & Number Participant quotations \\
& of \\
& mentions
\end{tabular}

Acquired familiarity with the hospital and healthcare team

29

Cultivated communication skills

Made a positive impact on patient affect

Engaged in an experience that will assist in career trajectory 9

Improved leadership skills

Experienced a challenging patient encounter
- I didn't know anything about Child Life Specialists before

- Nurses are really receptive and friendly-especially if we introduced ourselves to them ahead of time

- I feel more comfortable speaking with patients and families

- Got more experience being that point person who [patients] talk to, and I didn't have to rely on someone else to mediate

- [Learned] to make eye contact and talk in a positive way and smile

- Patients really do seem a lot happier

- When we were leaving, he said to his mom, "mom, I feel better" so that was nice. We are really able to cheer these patients up

- It reinforced that every interaction with a patient doesn't have to purely be about the treatment or diagnosis

- You don't have to be super serious all the time with your patients; you could be friendly and joke around while still doing your job

- Doing magic with patients is, in a way, de-stressing for me [...] I have more focus and energy to study after interacting with patients

- It's good to see how happy patients can be after a trick-helps reinforce why we are studying in the first place

- It's a good way to have fun out of class

- Volunteering for kids has really changed my perspective. [Pediatrics] is something that is back in the picture

- Makes me want to go into Pediatrics even more than when I started

- I think this is helping me learn to teach people and really becoming a mentor for other students

- Age groups in the early teens are difficult. One time, I was talking to a 6th grader-he was just really tired 
without taking too much time away from academic activities. All students considered their experiences in MagicAid as helpful towards their future careers as physicians and valuable to them as medical students.

In written reflection, this cohort of students identified skills they believe were learned within the MagicAid program. Responses included how to work with children, make pediatric patients feel comfortable, read body language and respond appropriately, and speak with patients (Supplemental Fig. 2).

\section{Online Survey}

One hundred forty-three students of a possible 539 participants (26.5\% participation rate) initiated completion of the online survey in March 2020. Thirteen students insufficiently completed responses ( $<50 \%$ of questions answered), and their answers were omitted from analysis, leaving 130 students' responses in the analyzed data pool $(24.1 \%$ completion rate). Participants included members from all relevant entering medical student classes (2016: 27 students, 2017: 32 students, 2018: 22 students, 2019: 45 students, other: 4 students). Sixty of these 130 students reported completing MagicAid training (46.2\% trained among survey participants), and forty-eight students reported engagement in at least one magic rounding session. Twenty-nine of those 48 student volunteers had engaged in clinical clerkships at the time of surveyance (32.2\% participation rate among trained volunteers who were in the clinical portion of medical school). A majority of students reported that they hold a very favorable or favorable view of student magicians in the patient's room (volunteers: 47/48, 97.9\%; all respondents: 119/129, 92.2\%; Supplemental Fig. 3).

Student volunteers responded to a subset of questions related to the impacts and their impressions of the program (Table 2). Volunteers unanimously reported the belief that the magic session was useful for the child, while a majority thought it was useful for the parents $(46 / 48,95.8 \%)$, staff $(33 / 48,68.8 \%)$, and the student $(45 / 48,93.8 \%)$. A majority of students reported that they were extremely satisfied or somewhat satisfied with their experiences in the program $(44 / 47,93.6 \%)$. Further, students reported that their involvement in the program improved their communication skills $(38 / 44,86.4 \%)$, reduced burnout in the preclinical years $(28 / 44,63.6 \%)$, and helped them get acclimated to the pediatric clerkship (19/29, 65.5\%). Students unanimously felt welcome in the patient's room during rounds, and a majority felt they were not a disturbance during the sessions (42/48, $87.5 \%)$. A subset of senior students reported using magic techniques with their patients in the clinical years $(7 / 29$, $24.1 \%$ ), and a majority reported experiences in MagicAid helped prepare them for clinical rotations $(15 / 29,51.7 \%)$.
Students who had trained but did not volunteer were asked why they chose not to volunteer. Of the twelve students who fit these criteria, eight responded to this question. Four main reasons were given: lack of confidence in magic skills $(n=4)$, scheduling and time constraints $(n=2)$, limited opportunity to volunteer and volunteering in another capacity instead $(n=2)$, and planning to volunteer but not yet able $(n=1)$.

\section{Discussion}

Through MagicAid, we introduced preclinical students to the art of medicine and cultivated the art of being attentive and present to the patient in all the complexity and meaning of his or her illness experience. We achieved our primary objectives, and the program was well received by students.

\section{Meaning and Emotional Well-being}

One matter that we investigated in our assessment was the "meaningfulness" component of the patient interactions-answering the questions, "do students believe they are making a difference, and do they experience increased well-being?" As reported, most trained students surveyed believed the therapy was useful for the child, parents, and staff. These findings are consistent with the previously reported opinions of physicians and nursing staff regarding MagicAid magic therapy [29] and show that students believe they are positively impacting others. Students remarked that they were able to "cheer...patients up" and that it was "good to see how happy patients" were after the interaction (Table 4). These statements offer additional support that MagicAid helped establish meaning in being a care provider at an early stage in medical school.

We further assessed this by evaluating student feelings of burnout, as loss of meaning is associated with increased burnout [30] and reducing burnout and promoting resilience was one of our goals. In our study, focus group participants were found to have experienced "psychological health benefits" as a result of participation in MagicAid, and a majority of survey respondents felt their experiences in the program helped reduce burnout in the clinical years. We postulate that joyful volunteer experiences in MagicAid may help to reinforce the meaning of patient care, which could serve as integral to student well-being and sense of renewal. This is consistent with prior literature on volunteerism, which has identified similar findings in service learning experiences [31]. In addition to the mental health benefits of volunteering, we also surmise that engagement with MagicAid may counter the reported decline in empathy among medical students in the clinical years [32], as other programs with patient interactions have been effective in improving 
empathic character [33] and service learning experiences in medical school are associated with increased empathy scores [34].

\section{Student Comfort in the Program}

We designed a program that would offer students a comfortable space to practice and learn, as some ECEs struggle in creating such a setting which detracts from the overall benefit $[6,7]$. Survey responses demonstrated that students unanimously felt welcome in patients' rooms; however, $12.5 \%$ of students perceived themselves to be a disturbance to staff, which was a higher figure than we expected. These students explained that they believed they may have been a disturbance by hindering access to the patient (Supplemental Fig. 2). On previous surveys of health professionals, $97 \%$ of providers (predominantly nurses and resident physicians) reported that student magicians were not a disturbance to patient care [29]. We conclude that the novelty of patient care and lack of experience in the inpatient setting for preclinical medical students informed this misperception.

\section{Preclinical Experiences as Preparation for Clinical Practice}

A large majority of students believed participation in the program improved their communication skills. In pediatrics, students remarked they had increased comfort in initiating and holding discussions with children due to their experiences, suggesting that the program was successful in improving student understanding of one of the unique aspects in caring for a child patient. Considering all clerkships holistically, a majority of respondents reported that experiences in MagicAid helped prepare them for clinical rotations with both adults and children. Students reported better relatability with patients and increased comfort in patient encounters while also finding more meaning in interactions with patients and families.

Prior investigation has linked increased preclinical patient contact with a smoother transition to the clinical years [35], which is consistent with our findings here. Comfort in these interactions is crucial to maximize learning in clinical training and ease the challenging transition from classroom to bedside with increased confidence [36, 37].

\section{Magic Programs and Their Benefits}

Outside of MagicAid, magic programs exist in many formats and with goals ranging from augmenting emotional and social interactions to improving psychological and physical well-being, both inside and outside of healthcare [19, 20, $38,39]$. However, MagicAid is unique in that it seeks to use magic as a modality for introducing students to patient care and is the only such program. Other programs engage volunteer magicians with patients [38-40]. Through this investigation, we discovered benefits in MagicAid similar to those identified in other magic programs, including increased motivation and concentration [41], increased work satisfaction and apparent improvement in energy and fatigue [42], and improved communication and public speaking skills [43]. Further, we previously published data showing our magic application improves anxiety of both pediatric patients and caregivers by approximately $25 \%$ within minutes of the therapy and suggested benefits in anxiety lasting to $1 \mathrm{~h} \mathrm{[29].}$

Our students founded a MagicAid 501(c)(3) non-profit organization with the primary mission of supporting the program at our institution and encouraging its expansion elsewhere [44]. The students act as officers and board members in a volunteer capacity. As a result of this organization, there are currently MagicAid medical student groups at three additional medical schools using our program as a model. The nonprofit facilitates maintenance of these groups and expansion to other sites.

\section{Limitations and Future Directions}

The program offers most of what we aspired for the creation of an empathic setting for early patient encounters in medical school, introduction of students to patients in the preclinical years, appreciation of the unique members of the healthcare team, and improvement of student well-being. However, limitations remain. While MagicAid garnered a lot of interest from students early in the preclinical years, we are limited to having a maximum of six student therapists rounding each week due to time availability of students and CCLSs. This limitation contributed to why some students did not volunteer on rounds after completion of training, as they no longer felt as comfortable or driven to volunteer. Thus, we have developed online tutorial videos to facilitate ongoing practice and host "jam sessions" where students can practice magic and team build with each other. After basic training, our center provides preclinical medical students with access to our hospital, which is housed in the same building as our medical school. For medical schools that are not based close to a hospital serving a pediatric population, it may be difficult to organize regular magic rounds.

Looking forward, we plan to further this program by introducing a longitudinal experience to foster an even closer connection between student and patient, which is currently in pilot. We anticipate this occurring in the setting of the oncology unit where many of the same patients return regularly for follow-up treatment. We also hope to broaden interdisciplinary work where our medical students work hand-in-hand with other health professional students. Additionally, we hope to include more structured feedback 
opportunities where students can be provided with written and structured feedback.

\section{Conclusions}

We believe that we succeeded in introducing future doctors to medicine as meaningful practitioners through empathic interactions in the setting of magic therapy. Through these uplifting early clinical experiences, students learned to better perceive the emotional state of their patients and to respond to them while gaining valuable pediatric patient exposure in an enjoyable activity. Students further developed their skills in leadership by precepting new students in patient encounters and working with allied health care professionals-shaping their professional identity in a way that embraces empathy and equal regard for all. Due to our positive experiences, we encourage the development of engaging, service learning programs in the medical humanities that serve as early clinical encounters introducing new medical students to patient care and developing their skills in compassionate care.

Supplementary Information The online version contains supplementary material available at https://doi.org/10.1007/s40670-021-01456-y.

Acknowledgements The authors wish to thank the many individuals who were pivotal in the development of this medical school group, including Dr. Hannah Lee, Dr. Sean Randazzo, Dr. Amanda Leng-Smith, Dr. Andrew Ramirez, Dr. Aldustus Jordan, Dianne Piscitelli, Michael Attard, Brooke Rose, Laura Brady, and Joan Alpers. Additionally, the authors thank all the student leaders, administrators, and donors who have facilitated the program and continue to assist in its success today.

Author Contribution Harrison D. Pravder, MD, is an Anesthesiology resident and corresponding author for this paper, Yale New Haven Hospital, Yale School of Medicine, New Haven, CT, USA. He was formerly a medical student at the Renaissance School of Medicine, Stony Brook, NY, USA. He is a past leader of the student group, cofounded the MagicAid non-profit organization, and serves as its vice president, secretary, and research director. David J. Elkin, MD, is a fellow in Sports Medicine at the Stanford University School of Medicine, Stanford, CA, having completed his Emergency Medicine residency at Maimonides Medical Center in Brooklyn, NY, USA. He was formerly a medical student at the Renaissance School of Medicine, Stony Brook, NY, USA. He is a past leader of the student group, co-founded the MagicAid non-profit organization, and currently serves as its president, treasurer, and magic director. Stephen G. Post, PhD, is a Professor of Family, Population and Preventive Medicine and the Founding Director of the Center for Medical Humanities, Compassionate Care and Bioethics at the Renaissance School of Medicine, Stony Brook, NY, USA. He serves as a faculty advisor of the MagicAid student group at the Renaissance School of Medicine. Maribeth B. Chitkara, MD, FAAP, is a Pediatric Hospitalist and Associate Professor of Pediatrics at Stony Brook Children's, Stony Brook, NY, USA. She serves as a faculty advisor of the MagicAid student group at the Renaissance School of Medicine.

Data Availability The datasets generated during and/or analyzed during the current study are available from the corresponding author on reasonable request.

\section{Declarations}

Ethics Approval and Consent to Participate The Institutional Review Board at Stony Brook University reviewed and approved this study (ID 1037793, Initial Approval 06/2017). Informed consent was obtained from all participants included in the study.

Competing Interests The authors declare no competing interests.

\section{References}

1. Marinker M. Why make people patients? J Med Ethics. 1975;1:81-4.

2. Dyrbye L, Shanafelt T. A narrative review on burnout experienced by medical students and residents. Med Educ. 2016;50:132-49. https://doi.org/10.1111/medu.12927.

3. Wilcox MV, Orlando MS, Rand CS, et al. Medical students' perceptions of the patient-centredness of the learning environment. Perspect Med Educ. 2017;6:44-50. https://doi.org/10.1007/ s40037-016-0317-x.

4. Dornan T, Littlewood S, Margolis SA, et al. How can experience in clinical and community settings contribute to early medical education? A BEME systematic review. Med Teach. 2006;28:318. https://doi.org/10.1080/01421590500410971.

5. Dornan T, Bundy C. What can experience add to early medical education? Consensus survey. BMJ. 2004;329:834. https://doi.org/ 10.1136/bmj.329.7470.834.

6. Briggs-Style C, Maxwell JA, Moore GT. The effects of early patient contact: the student's perspective. Acad Med. 1990;65:S33-34. https://doi.org/10.1097/00001888-199009000-00031.

7. Schei E, Knoop HS, Gismervik MN, et al. Stretching the comfort zone: using early clinical contact to influence professional identity formation in medical students. J Med Educ Curric Dev. 2019. https://doi.org/10.1177/2382120519843875.

8. Ahrweiler F, Scheffer C, Roling G, et al. Clinical practice and self-awareness as determinants of empathy in undergraduate education: a qualitative short survey at three medical schools in Germany. GMS Z Med Ausbild. 2014;31:Doc46. https://doi.org/ 10.3205/zma000938.

9. Hojat M. Ten approaches for enhancing empathy in health and human services cultures. J Health Hum Serv Adm. 2009;31:412-50.

10. Wald HS, McFarland J, Markovina I. Medical humanities in medical education and practice. Med Teach. 2019;41:492-6. https:// doi.org/10.1080/0142159X.2018.1497151.

11. Peabody FW. The care of the patient. J Am Med Assoc. 1927;88:87782. https://doi.org/10.1001/jama.1927.02680380001001.

12. Todd C. Curriculum inventory in context. AAMC. 2016.

13. Gordon J. Medical humanities: to cure sometimes, to relieve often, to comfort always. Med J Aust. 2005;182:5-8. https://doi.org/10. 5694/j.1326-5377.2005.tb06543.x.

14. Wald HS, Haramati A, Bachner YG, Urkin J. Promoting resiliency for interprofessional faculty and senior medical students: outcomes of a workshop using mind-body medicine and interactive reflective writing. Med Teach. 2016;38:525-8. https://doi.org/ 10.3109/0142159X.2016.1150980.

15. Mangione S, Chakraborti C, Staltari G, et al. Medical students' exposure to the humanities correlates with positive personal qualities and reduced burnout: a multi-institutional U.S. survey. J Gen Intern Med. 2018;33:628-34. https://doi.org/10.1007/ s11606-017-4275-8.

16. Graham J, Benson LM, Swanson J, et al. Medical humanities coursework is associated with greater measured empathy in medical students. Am J Med. 2016;129:1334-7. https://doi.org/10. 1016/j.amjmed.2016.08.005. 
17. UCLA Arts \& Healing. UCLA medical students bring therapeutic arts to patients. 2018. https://uclartsandhealing.org/ucla-medicalstudents-bring-therapeutic-arts-to-patients/. Accessed 25 Feb 2021.

18. Hellmuth E. Embracing the therapeutic power of the arts in patient care. In: Arts and Education Council of St. Louis. 2018. https://keeparthappening.org/blog/impact-individuals/embracingtherapeutic-power-arts-patient-care. Accessed 25 Feb 2021.

19. Lam MT, Lam HR, Chawla L. Application of magic in healthcare: a scoping review. Complement Ther Clin Pract. 2017;26:5-11. https://doi.org/10.1016/j.ctcp.2016.11.002.

20. Bagienski S, Kuhn G, World Health Organization. Beyond the crossroads of magic, health, and wellbeing. Public Health Panor. 2020;6:155-71.

21. Green D, Schertz M, Gordon AM, et al. A multi-site study of functional outcomes following a themed approach to hand-arm bimanual intensive therapy for children with hemiplegia. Dev Med Child Neurol. 2013;55:527-33. https://doi.org/10.1111/dmcn.12113.

22. Weinstein M, Myers V, Green D, et al. Brain plasticity following intensive bimanual therapy in children with hemiparesis: preliminary evidence. In: Neural plasticity. 2015. https://www.hindawi. com/journals/np/2015/798481/. Accessed 25 Feb 2021.

23. Schertz M, Shiran SI, Myers V, et al. Imaging predictors of improvement from a motor learning-based intervention for children with unilateral cerebral palsy. Neurorehabil Neural Repair. 2016;30:647-60. https://doi.org/10.1177/1545968315613446.

24. Vagnoli L, Caprilli S, Robiglio A, Messeri A. Clown doctors as a treatment for preoperative anxiety in children: a randomized, prospective study. Pediatrics. 2005;116:e563-7. https://doi.org/ 10.1542/peds.2005-0466.

25. Pitt MB. Magical thinking: how learning to act like a magician can make you a better physician. Pediatrics. 2020. https://doi.org/ 10.1542/peds.2020-0420.

26. Elkin DJ, Pravder HD. Bridging magic and medicine. The Lancet. 2018;391:1254-5. https://doi.org/10.1016/S0140-6736(18)30707-4.

27. Council COHC and CL. Child life services. Pediatrics. 2014;133:e1471-8. https://doi.org/10.1542/peds.2014-0556.

28. Thomas DR. A general inductive approach for analyzing qualitative evaluation data. Am J Eval. 2006;27:237-46. https://doi.org/ 10.1177/1098214005283748.

29. Pravder HD, Leng-Smith A, Brash AI, et al. A magic therapy program to alleviate anxiety in pediatric inpatients. Hosp Pediatr. 2019;9:942-8. https://doi.org/10.1542/hpeds.2019-0212.

30. Post SG. Altruism and health: perspectives from empirical research. New York, NY, US: Oxford University Press; 2007.

31. Konrath S. The power of philanthropy and volunteering. In: Wellbeing: a complete reference guide. American Cancer Society; 2014. pp. 1-40.

32. Neumann M, Edelhäuser F, Tauschel D, et al. Empathy decline and its reasons: a systematic review of studies with medical students and residents. Acad Med. 2011;86:996-1009. https://doi. org/10.1097/ACM.0b013e318221e615.

33. Fragkos KC, Crampton PES. The effectiveness of teaching clinical empathy to medical students: a systematic review and metaanalysis of randomized controlled trials. Acad Med. 2020;95:94757. https://doi.org/10.1097/ACM.0000000000003058.

34. Brazeau CMLR, Schroeder R, Rovi S, Boyd L. Relationship between medical student service and empathy. Acad Med. 2011;86:S42. https://doi.org/10.1097/ACM.0b013e31822a6ae0.
35. Godefrooij MB, Diemers AD, Scherpbier AJ. Students' perceptions about the transition to the clinical phase of a medical curriculum with preclinical patient contacts; a focus group study. BMC Med Educ. 2010;10:28. https://doi.org/10.1186/1472-6920-10-28.

36. Prince KJAH, Van De Wiel M, Scherpbier AJJA, et al. A qualitative analysis of the transition from theory to practice in undergraduate training in a PBL-medical school. Adv Health Sci Educ Theory Pract. 2000;5:105-16. https://doi.org/10.1023/A:1009873003677.

37. Radcliffe $\mathrm{C}$, Lester $\mathrm{H}$. Perceived stress during undergraduate medical training: a qualitative study. Med Educ. 2003;37:32-8. https://doi.org/10.1046/j.1365-2923.2003.01405.x.

38. Hart R, Walton M. Magic as a therapeutic intervention to promote coping in hospitalized pediatric patients. Pediatr Nurs. 2010;36:11-6.

39. Wiseman R, Watt C. Achieving the impossible: a review of magic-based interventions and their effects on wellbeing. PeerJ. 2018;6:e6081. https://doi.org/10.7717/peerj.6081.

40. Bagienski S, Kuhn G. The crossroads of magic and wellbeing: a review of wellbeing-focused magic programs, empirical studies, and conceivable theories. Int J Wellbeing. 2019;9(2):41-65. https://doi.org/10.5502/ijw.v9i2.740.

41. Spencer K. Hocus focus: evaluating the academic and functional benefits of integrating magic tricks in the classroom. JIASE. 2012;13:87-99.

42. Kwong E, Cullen N. Teaching magic tricks to patients as an adjunct to their rehabilitation program. In: Poster presented at the Annual Scientific Meeting of the Canadian Association of Physical Medicine and Rehabilitation. Toronto, Canada. 2007.

43. Papalaskari MA, Hess K, Lagalante A, et al. Work in progress engineering the magic school creativity and innovation in context. In: 2007 37th Annual Frontiers In Education Conference - Global Engineering: Knowledge Without Borders, Opportunities Without Passports. 2007. pp. S2B-1-S2B-2.

44. MagicAid 501(c)(3) Website. In: MagicAid. 2021. https://www. magic-aid.org. Accessed 2 Mar 2021.

45. Carson AJ, Dias S, Johnston A, et al. Mental health in medical students a case control study using the 60 item general health questionnaire. Scott Med J. 2000;45:115-6. https://doi.org/10. 1177/003693300004500406.

46. Rosal MC, Ockene IS, Ockene JK, et al. A longitudinal study of students' depression at one medical school. Acad Med. 1997;72:5426. https://doi.org/10.1097/00001888-199706000-00022.

47. West CP, Shanafelt TD, Kolars JC. Quality of life, burnout, educational debt, and medical knowledge among internal medicine residents. JAMA. 2011;306:952-60. https://doi.org/10.1001/jama. 2011.1247.

48. Irby DM, Cooke M. O'Brien BC. Calls for reform of medical education by the Carnegie Foundation for the Advancement of Teaching: 1910 and. Acad Med. 2010;85:220-7. https://doi.org/ 10.1097/ACM.0b013e3181c88449.

49. Yardley S, Littlewood S, Margolis SA, et al. What has changed in the evidence for early experience? Update of a BEME systematic review. Med Teach. 2010;32:740-6. https://doi.org/10.3109/ 0142159X.2010.496007.

Publisher's Note Springer Nature remains neutral with regard to jurisdictional claims in published maps and institutional affiliations. 